SI'sOMOS AMERICANOS Revista de Estudios Transfronterizos
Volumen XIX, número 1,

enero-junio 2019.

Recibido: 19 de enero de 2018.

Aprobado: 26 de marzo de 2019.

\title{
Dinámica contemporánea de los vínculos transnacionales. Estudio de caso de una comunidad migrante en el sur del Estado de México*
}

\section{Contemporary dynamics of transnational links. Case study of a migrant community in the south of the State of Mexico}

Ana Elizabeth Jardón Hernández**

Centro de Investigación en Ciencias Sociales y Humanidades de la Universidad Autónoma del Estado de México, México.

Itzel Hernández Lara***

Facultad de Ciencias Políticas y Sociales de la Universidad Autónoma del Estado de México

Cómo citar este artículo: Jardón, A. y Hernández, I. (2019). Dinámica contemporánea de los vínculos transnacionales. Estudio de caso de una comunidad migrante en el sur del Estado de México.

Si Somos Americanos, 19(1), pp.67-84.

DOI: $10.4067 / \mathrm{S} 0719-09482019000100067$

\section{Resumen}

A partir de los argumentos que sustenta la perspectiva teórica transnacional, en este trabajo retomamos el concepto de prácticas transnacionales para reflexionar sobre los lazos, los vínculos y la puesta en marcha de diversas actividades que desdibujan las fronteras entre la población migrante y no migrante en espacios rurales de México. Para ello, recurrimos al uso de técnicas cualitativas que nos permitieron reconstruir la historia migratoria de la

\footnotetext{
Este artículo está basado en la tesis doctoral Nuevos escenarios en los procesos de organización social de la migración internacional en Las Vueltas, Estado de México, El Colegio de Michoacán, de Ana Jardón, en el que se analizan nuevos resultados sobre los vínculos transnacionales.

** Doctora en Ciencias Sociales, El Colegio de Michoacán; profesora-investigadora, Centro de Investigación en Ciencias Sociales y Humanidades de la Universidad Autónoma del Estado de México; investigadora nacional nivel 1. Correo electrónico: ileana.14@hotmail.com

*** Doctora en Ciencias Sociales, El Colegio de México; profesora-investigadora, Facultad de Ciencias Políticas y Sociales de la Universidad Autónoma del Estado de México; investigadora nacional nivel C. Correo electrónico: itzelina_hl@yahoo.com.mx
} 
comunidad de estudio e identificar los recursos que han trascendido en la configuración de vínculos transnacionales entre los habitantes de Las Vueltas (Coatepec Harinas, Estado de México) y su población migrante asentada en Woodstock (Illinois, Estados Unidos). A través de tres ejemplos ofrecemos un acercamiento para entender este tipo de prácticas económicas, políticas, sociales y culturales como vínculos transnacionales que aproximan y unen a estas poblaciones, aunque al mismo tiempo desencadenan diversos conflictos ante la posición que adquiere el migrante colectivo que envía remesas y participa activamente en los procesos de organización comunitaria.

Palabras clave: migración, prácticas transnacionales, Estado de México.

\begin{abstract}
Based on the arguments that sustain the transnational theoretical perspective, in this paper we return to the concept of transnational practices to reflect on the ties, links and implementation of various activities that blur the boundaries between the migrant and nonmigrant population in rural areas of Mexico. We employ qualitative techniques that allow us to reconstruct the migratory history of the community under study and identify the resources that have transcended the configuration of transnational links between the inhabitants of Las Vueltas (Coatepec Harinas, State of Mexico) and their migrant population in Woodstock (Illinois, United States). We use three examples to develop an approach to economic, political, social and cultural practices as transnational links that connect and unite these populations even as they trigger a wide range of conflicts related to the position acquired by the migrant collective that sends remittances and actively participates in processes of community organization.
\end{abstract}

Keywords: migration, transnational practices, State of Mexico.

\title{
Introducción
}

El transnacionalismo como campo de investigación en las migraciones internacionales ha sido analizado desde diferentes posiciones, las que han favorecido la construcción de un entramado de conceptos diversos, cuyo objetivo ha sido dar cuenta de los mecanismos de articulación económica, social y política entre comunidades distantes y separadas geográficamente, donde la transmigración y el transmigrante se presentan como las nuevas figuras que asume la movilidad poblacional en el mundo.

La corriente transnacional de la migración imprime utilidad en el desarrollo de este trabajo, en la medida en que ha permitido analizar los vínculos que los migrantes salvaguardan con sus espacios de origen, en lugar de entender la migración como un proceso que obliga al 68 Si Somos Americanos. Revista de Estudios Transfronterizos 
individuo a suspender las relaciones con su país de procedencia (Hondagneu, 2007). De ahí que nuestro texto tiene por objetivo documentar la dinámica y presencia de un conjunto de diversas prácticas transnacionales económicas, políticas y sociales en la comunidad de Las Vueltas, Estado de México, mismas que se vinculan entre sí y responden tanto a la tradición migratoria de la comunidad, como a la capacidad de organización de su población migrante y no migrante.

Para abordar lo antes mencionado, el texto está conformado por tres grandes apartados. El primero ofrece algunas reflexiones sobre migración y transnacionalismo, que nos permiten puntualizar nuestro interés por retomar el concepto de prácticas transnacionales como un conjunto de actividades diversas que han venido cobrando presencia importante entre la población migrante y no migrante en la comunidad de estudio. En un segundo apartado, se recuperan elementos generales sobre la historia migratoria de la comunidad, para identificar los momentos que en el mismo proceso migratorio propiciaron la creación de tales vínculos transnacionales. En el último apartado se presentan tres casos que, por un lado, ponen en evidencia el involucramiento de la población vuelteña en prácticas que vinculan a los de 'aquí' (en México) y a los de 'allá' (en Estados Unidos), pero que por otro abordan prácticas que revelan una serie de desencuentros y rivalidades entre la población que activa estas dinámicas.

\section{Migración y transnacionalismo}

Hacia la última década del siglo XX, el transnacionalismo surgió como una propuesta analítica para estudiar el fenómeno migratorio internacional, desde una mirada que reconoce los vínculos que los migrantes mantienen con sus lugares de origen y las repercusiones sociales que se derivan de estas. Glick Schiller, Basch y Blanc-Szanton (1992) proponen el término transnacionalismo para hacer énfasis en la emergencia de un proceso social en el que la población migrante construye campos sociales que atraviesan fronteras geográficas, culturales y políticas.

Desde esta perspectiva se entiende que, en la práctica, los migrantes son transmigrantes que desarrollan y mantienen múltiples relaciones (familiares, económicas, sociales, organizacionales, religiosas y políticas) que vinculan al menos dos espacios geográficamente separados y ubicados en distintos países. En otras palabras, esto supone que los transmigrantes actúan, toman decisiones y experimentan ciertas preocupaciones dentro de un campo de relaciones sociales que vinculan a su país de origen y su país (o países) de asentamiento (Glick Schiller, Basch y Blanc-Szanton, 1992).

Analíticamente, el transnacionalismo plantea la necesidad de superar el divorcio entre los estudios desde el país de origen y los llevados a cabo en el país de acogida. Esto es, romper con la idea de espacios separados, como una forma para acercarse a la experiencia de la 
población migrante en un contexto global (Ariza y Portes, 2007) y de interdependencia económica. En otras palabras, entender las vidas de un número creciente de individuos no solamente desde lo que sucede dentro de las fronteras nacionales (Levitt y Glick Schiller, 2006), sino más allá de estas, superando la idea de los Estados como 'contenedores' y límites únicos de los procesos sociales (Rivera, 2007).

Desde el transnacionalismo se han propuesto diversos términos para analizar los espacios de acción social asociados a la migración transnacional, como arenas de relaciones sociales. Por ejemplo, Levitt y Glick Schiller (2006) proponen el término campo social transnacional para referirse a un conjunto de múltiples redes de relaciones sociales a través de las que se intercambian de manera desigual, se organizan y se transforman ideas, prácticas y recursos. Desde esta perspectiva, hay diferencias entre las formas de ser y las formas de pertenecer a dicho campo. Por un lado, las formas de ser se refieren a las relaciones y prácticas sociales reales en las que participan los individuos, más que a identidades asociadas con sus acciones, pues los sujetos pueden estar incorporados a un campo social, pero no reconocerse con un membrete asociado a este. Mientras que las formas de pertenecer se refieren a las prácticas concretas que apuntan o actualizan una identidad, y que demuestran un contacto consciente con un grupo particular. En los campos sociales transnacionales, los individuos combinan las formas de ser con las formas de pertenecer de distintas maneras, siendo incluso posible que ambas se presenten de manera simultánea, aunque no necesariamente (Levitt y Glick Schiller, 2006).

Otra concepción asociada a este entramado de relaciones es la noción de espacio social transnacional, entendido como combinaciones de vínculos sociales y simbólicos, posiciones en redes y organizaciones, así como redes de organizaciones que atraviesan las fronteras de múltiples Estados nación (Faist, 2000, 2006). Estos espacios denotan procesos sociales, culturales, políticos y económicos dinámicos en los que participan personas y colectivos (migrantes y no migrantes), que están constreñidos por las regulaciones impuestas por dichos Estados, al tiempo que involucran la acumulación y uso de varios tipos de capital (económico, humano y social), que son transmitidos a través de vínculos sociales y simbólicos (Faist, 2000).

Esto no implica que los migrantes sean personas desterritorializadas y que las prácticas transnacionales que vinculan los diversos lugares a través de las fronteras se lleven a cabo de manera libre, sin las restricciones y oportunidades que imponen los contextos específicos (Guarnizo y Smith, 1999). Así como las comunidades transnacionales son sensibles a las tecnologías de la comunicación, también lo son al capital y las políticas de control estatal, especialmente a las políticas migratorias.

Cabe decir entonces que estas comunidades se mantienen a través de una serie de prácticas transnacionales que incluyen el intercambio de información, bienes materiales y simbólicos, así como mecanismos para la participación política, económica y cultural de migrantes y no migrantes en ambos países. Estas prácticas cumplen una importante función 
de conexión, que permiten mantener y fortalecer los vínculos entre los pueblos de origen y los lugares de recepción de los migrantes, en la medida en que contribuyen al mantenimiento de la vida comunitaria más allá del territorio de origen (el pueblo, la comunidad), y permiten la construcción de una existencia 'simultánea' de los miembros de la comunidad, rearticulando al mismo tiempo la experiencia fragmentada del territorio (Velasco, 2002).

Para llevar a cabo estas prácticas transnacionales se hace uso de diversos recursos, tanto en los lugares de origen como de asentamiento: relaciones sociales y de parentesco, tecnologías de transporte y comunicación, repertorios simbólicos, entre otros. Importante es decir que no todos los migrantes asentados llevan a cabo prácticas transnacionales, y que aquellos que lo hacen no lo realizan de manera homogénea, sino que varían en fuerza y formalidad (Guarnizo 2007; Levitt, DeWind y Vertovec, 2003; Portes, 2005). Las prácticas transnacionales pueden abarcar ámbitos distintos (económico, político, religioso, familiar y sociocultural) y varían de acuerdo a su formalidad. Asimismo, se registran diferencias en las formas de involucrarse en este tipo de prácticas según el género, la edad, el capital humano, el estatus migratorio y la disponibilidad de redes en los distintos colectivos de migrantes (Dore et al., 2003; Giorguli e Itzigsohn, 2006; Guarnizo, Portes y Haller, 2003; Portes, 2005).

En el caso de la migración México-Estados Unidos, se ha destacado el papel que juegan las organizaciones de migrantes en la articulación de un espacio social transnacional entre los lugares de origen y recepción. Desde la perspectiva de Velasco (2002), las organizaciones de migrantes funcionan como un mecanismo rearticulador del territorio, que da una base local a un contingente de población disperso y en movimiento. Aunque la acción social de los sujetos es fundamental, no se debe confundir a las asociaciones con las comunidades transnacionales, pues estas últimas pueden existir sin la necesidad de agrupaciones formales.

Algunos migrantes participan dentro de estructuras institucionalizadas, mientras que otros lo hacen a través de relaciones más informales y flexibles (Levitt, DeWind y Vertovec, 2003). Al respecto, Dore et al. (2003) establecen una distinción entre prácticas transnacionales 'amplias' y 'estrechas', como dos polos a lo largo de un continuum definido por el grado de institucionalización, el movimiento dentro del campo transnacional o la participación en prácticas transnacionales. Estas prácticas pueden ser económicas, políticas, cívico-sociales y culturales, aunque reconocen que estas divisiones pueden ser arbitrarias, pues las mismas personas involucradas en una actividad transnacional pueden ser incluidas en diferentes categorías (Dore et. al., 2003).

La transnacionalidad en sentido 'estrecho' incluye a las personas involucradas en prácticas económicas, políticas y sociales que implican un movimiento habitual en un campo geográfico transnacional, con un alto nivel de institucionalización o una participación personal constante. Por su parte, la transnacionalidad, en sentido 'amplio', se refiere a una 
serie de prácticas materiales y simbólicas que implican un movimiento físico esporádico entre dos países y un bajo nivel de institucionalización. De acuerdo con estos autores, la suma de las prácticas transnacionales, en sentido amplio y estrecho, constituye el campo social transnacional.

No obstante, es importante señalar que la participación regular en las actividades transnacionales caracteriza tan solo a una minoría de los migrantes (Portes, 2005). A diferencia de las prácticas transnacionales propias de la esfera pública, el número de personas involucradas en actividades ocasionales e informales -incluidas prácticas sociales, culturales y religiosas, en respuesta a elecciones, recesiones económicas, eventos del ciclo de vida, desastres climáticos- es mucho mayor (Levitt y Jaworsky, 2007).

A partir de estas nociones generales, en el desarrollo de este trabajo retomamos el concepto de prácticas transnacionales para entender los vínculos económicos, sociales y culturales que han sido construidos entre los habitantes de Las Vueltas, Coatepec Harinas, Estado de México, y su población establecida en Woodstock, Illinois, Estados Unidos. Abordar mediante este estudio de caso dicho concepto nos permitirá distinguir no solo entre los tipos de prácticas, sino en la formalidad de estas y en las formas de participación de esta población, cuyos procesos de organización además de propiciar y fortalecer la comunicación con las y los migrantes en Estados Unidos, han venido a contribuir en la asignación de apoyos y ejecución de obras para mejorar la infraestructura de esta comunidad rural.

\section{Metodología}

Desde un enfoque cualitativo, este trabajo se sustentó en dos técnicas de investigación: observación participante y entrevistas en profundidad, que nos permitieron recuperar las voces de determinadas personas migrantes. La primera se desarrolló como una estrategia de interacción, de nuestra parte, en la vida de la comunidad y en la cotidianeidad de los vuelteños. Aquí, algunas situaciones como participar de la misa dominical y de las celebraciones comunitarias nos fueron útiles para crear confianza entre la población acerca de la investigación y para recabar testimonios invaluables, algunos de ellos mediante pláticas informales.

El perfil de los informantes fue diverso, en tanto se identificaron líderes comunitarios que han participado en obras diversas para el mejoramiento del pueblo, así como en la gestión de apoyos para la población de esta comunidad. De esta manera, el primer acercamiento a la comunidad se realizó a través del representante de migrantes en Las Vueltas, quien a su vez nos facilitó el contacto con el delegado y otros habitantes que han sido representantes comunitarios y/o que han participado en la ejecución de proyectos de obra y organización de actividades en dicho lugar. El acercamiento con estos informantes se realizó con la

\section{Si Somos Americanos. Revista de Estudios Transfronterizos}


finalidad de conocer tanto acerca de los procesos de organización comunitaria, como de las formas en que estos se vinculan con la migración internacional y la configuración de prácticas transnacionales.

Así fue que, poniendo en el centro del análisis las experiencias y perspectivas de la población entrevistada, recopilamos información sobre los procesos de organización social comunitaria, además de que buscamos reconstruir la historia migratoria de la comunidad, así como identificar los vínculos con su población migrante en Estados Unidos y las formas en que dichos lazos se constituyen como un conjunto de prácticas transnacionales. En total se aplicaron 21 entrevistas (todas con el consentimiento informado de las y los entrevistadas/os), que nos permitieron dimensionar la dinámica migratoria en la comunidad, los procesos de gestión del club de migrantes y su incidencia en la implementación de proyectos comunitarios que ponen en evidencia la presencia de prácticas transnacionales económicas, políticas y sociales.

La recopilación de la información se derivó de la investigación de campo que se realizó para el desarrollo de la tesis doctoral Nuevos escenarios en los procesos de organización social de la migración internacional en Las Vueltas, Estado de México, cuyas dimensiones de análisis fueron más amplias que los resultados que aquí presentamos. Esto, con la finalidad de discutir la importancia que las prácticas transnacionales han cobrado en las formas de organización social asociadas con los procesos migratorios de las personas y los hogares en esta comunidad.

Cabe decir que los primeros acercamientos al pueblo de Las Vueltas se realizaron en 2010, siendo en 2011 cuando se llevó la investigación de campo con un mayor nivel de profundidad. En 2017 revisitamos la comunidad, con la finalidad de observar las dinámicas comunitarias y en su caso reconocer algunos cambios en los procesos de organización de esta.

\section{Breve historia de la migración internacional en Las Vueltas}

Los procesos migratorios de la población en Las Vueltas si bien se inician con el Programa Bracero, en ese mismo período fueron cobrando una presencia cada vez más numerosa. En 1964, con la anulación del Programa Bracero, los migrantes de esta comunidad se separaron laboralmente de Estados Unidos por un espacio de aproximadamente tres años, pues según la historia oral de la población migrante de Las Vueltas, los campesinos contratados como braceros regresaron a su pueblo de origen al término de su relación laboral.

A partir de 1970 empieza a cimentarse la intensidad en las migraciones internacionales de los vuelteños. En estos desplazamientos, el perfil de los primeros emigrantes vuelteños continuó siendo predominantemente masculino, en edades de entre 30 y 40 años; es decir, 
se trataba exclusivamente de hombres jefes de hogar en edades aunque productivas, avanzadas en relación con los cambios que pocos años después registraría este patrón.

Woodstock, Illinois, fue el principal destino de los primeros migrantes irregulares. Entre 1970 y 1973 se estima que únicamente fueron alrededor de ocho individuos los que emigraron a Estados Unidos, lo cual se explica tanto por el miedo de emigrar, como por la insuficiente solvencia económica para pagar un coyote o pollero, a sabiendas de que emigraban por necesidad y falta de dinero.

A partir de 1974 se registraron las primeras emigraciones en grupo, cuando los ya establecidos en Woodstock "corrieron la voz de que allá había mucho trabajo y pagaban bien" (Modesto, 65 años). Cabe agregar que en ese año fue también cuando se incorporaron a este proceso emigrantes de los cinco barrios de Las Vueltas, con la intención de cruzar la frontera 'de contrabando' y trabajar en Estados Unidos.

Así pues, si bien la diversificación de los destinos en Estados Unidos se inició en 1979, con New Jersey y Pennsylvania, se presentó como un proceso asociado a la reestructuración de los mercados de trabajo, la estacionalidad de los empleos agrícolas y la conveniencia de trabajar en los 'ranchos', donde algunas veces los trabajadores migrantes recibían alojamiento y alimentación.

A partir de 1983 comenzó un proceso de dispersión en los patrones de establecimiento, facilitado por la experiencia laboral que había logrado parte de esta población migrante, así como por el aprendizaje y dominio del idioma inglés. La diversificación de los lugares de llegada se acentuó después de la Ley de Reforma y Control de la Inmigración (IRCA, por sus siglas en inglés), dada la oportunidad que representó para la mayor movilidad y el acceso al mercado de trabajo bajo condiciones legales. Con todo y esta diversificación, Woodstock continuó presentándose como el principal destino de la migración de los vuelteños, pues la densa presencia de familiares y amigos que podían 'echarle la mano' a los nuevos migrantes hacía poco menos problemática y más llevadera la estancia e incorporación laboral en aquella localidad.

Finalmente, el proceso de masividad migratoria acompañado de la cada vez mayor cantidad de migraciones familiares fue acentuando los patrones de despoblamiento comunitario, deserción y disminución de la matrícula escolar, descuido de las parcelas y dependencia de las remesas en Las Vueltas.

Ante el proceso de despoblamiento local se observó también que la masividad y concentración de la migración vuelteña fortaleció los vínculos entre 'los de aquí' y 'los que están allá', puesto que el arraigo y sentido de pertenencia de la población migrante en Estados Unidos ha permitido el ejercicio de diversas prácticas dirigidas a fortalecer los vínculos sociales, económicos y políticos comunitarios. 


\section{Acercamiento a las prácticas transnacionales de la población en Las Vueltas}

La historia y los patrones de comportamiento migratorio de los vuelteños hacia Estados Unidos han permitido crear vínculos sociales, económicos, políticos y culturales que han trascendido en las formas de organización familiar y comunitaria, al tiempo que, según Becerril (2007), resaltan la agencia humana, la subjetividad y las estrategias puestas en juego por los migrantes, como actores relevantes que pueden transformar las estructuras sociales y políticas a su alrededor.

El ejercicio de las diversas prácticas transnacionales que se exponen a continuación parece registrar una dinámica semejante en la región migratoria de Coatepec Harinas, donde Baca (2011) advierte que las movilidades y prácticas transnacionales han adquirido una vigorosa y diversificada presencia en los últimos 20 años, puesto que la antigüedad migratoria de la región está abonando a la construcción de un espacio social transnacional, fortalecido por la presencia de redes sociales que permiten la conexión entre el origen y los destinos de la población migrante. En otros términos, la autora sostiene que las comunidades de migrantes de la región migratoria Coatepec Harinas han construido lógicas de funcionamiento y reproducción de la movilidad transnacional.

Ejemplo de ello pueden ser la formación de redes sociales, el envío de remesas, el retorno, la desterritorialización de la familia, la implicación en asociaciones de migrantes y la promoción de proyectos para el desarrollo comunitario (Guarnizo y Smith, 1999), de las cuales retomaremos tres ejemplos de lo observado en el pueblo de Las Vueltas, con la finalidad de realizar un acercamiento al ejercicio de las prácticas que han favorecido la creación de vínculos transnacionales de distinta índole, y donde la religión parece posicionarse entre los principales factores que han trascendido en las formas de organización comunitaria.

\section{La fiesta patronal}

Un primer ejemplo lo constituye la fiesta patronal en honor a la Santa Cruz, que se realiza en la primera semana de mayo de cada año, y que representa una de las principales tradiciones religiosas vinculadas con los procesos migratorios internacionales. Si bien esta fiesta se ha venido celebrando desde 1927, la magnitud del evento ha cambiado según las posibilidades económicas de los lugareños.

En los primeros años de la migración irregular, cuando la movilidad internacional de esta población surgió como un proceso para la generación de ingresos monetarios, nació también como proyecto, aunque no formalizado, la idea de que cada migrante vuelteño en Estados Unidos aportara cinco dólares semanales a sus comunidades de origen, con el propósito de recaudar fondos que permitiesen solventar los gastos de la fiesta patronal. Siendo este el origen de las llamadas remesas prestigio, que son las utilizadas para solventar los gastos efectuados en fiestas y celebraciones que otorgan prestigio a la población migrante que envía, además de que le permiten asegurar la pertenencia y el apoyo comunitario (Durand, 2007). 
En torno a esta celebración, el envío de remesas prestigio se ha venido construyendo como una práctica económica transnacional, que a su vez tiene importantes significados sociales y asegura la pertenencia y el apoyo comunitario, pues la no aportación implica conductas de segregación y exclusión de las familias y trabajadores en Estados Unidos que no contribuyen para tal objetivo.

Más allá de esta aportación que establece importantes vínculos económicos entre los emigrantes y su comunidad de origen, son otras las prácticas que se conjugan entre la organización y la propia celebración patronal, las que permiten consolidar las redes sociales, conservar los lazos afectivo-sociales con quienes se han quedado atrás, resaltando el papel de los migrantes como actores sociales y políticos relevantes. Entre estas prácticas surge un entramado de múltiples actividades durante el proceso de organización de la fiesta y el festejo en sí mismo.

La Mayordomía, como una organización transnacional, está integrada por habitantes de Las Vueltas y vuelteños residentes en Toluca, Ciudad de México y Estados Unidos. Sin embargo, el proceso de organización, cobranza, publicidad, vigilancia y control durante los días de la fiesta es responsabilidad de los integrantes de la Mayordomía local. En Estados Unidos existe un comité de cobranza de aproximadamente 18 personas, de las cuales 10 son responsables de recolectar las cooperaciones en Woodstock y el resto lo hace en los diferentes estados donde radica población vuelteña. A su vez, los cobradores responsables por ciudad convocan a reuniones abiertas para establecer acuerdos sobre la organización de la fiesta, pero únicamente en lo relativo con los grupos o bandas musicales que participarán.

Esta fase de la organización de la fiesta quizás se presenta como uno de los momentos más conflictivos, debido a que la comunicación transfronteriza (telefónica y por internet) para concretar acuerdos se traduce en diversas inconformidades e incluso rivalidades entre los de aquí y los de allá, pues finalmente en el intento por establecer acuerdos en reuniones de escasa o nula asistencia se entablan relaciones económicas de poder, dado que aportar más otorga el derecho de decidir. Por su mayor recaudación, de aproximadamente 59\% de los ingresos requeridos para el evento, se dice que la fiesta es un 'halago para los norteños', porque son ellos quienes deciden sobre la coordinación artística de la fiesta e incluso también sobre los días en los que habrá de efectuarse la celebración.

Aunque no existe una cuota fija para la cooperación, el promedio oscila entre los 250 y 200 dólares por trabajador en Estados Unidos, mientras que en Las Vueltas el promedio por hogar fluctúa entre 1.500 y 3.000 pesos. Así, a sabiendas de que "si eres del pueblo, ya sabes que tienes que dar [cooperar]" (Emiliano, 33 años), las respuestas de no cooperación además de desacreditar y señalar a la familia, disminuyen la posibilidad para que estas puedan contar con el apoyo comunitario en caso de requerir algún servicio. Incluso se ha fomentado como práctica discriminatoria, ya que posterior a la rendición de cuentas, se elaboran 'listas negras' que incluyen los nombres de los que no cooperaron, se turnan al 
delegado y es este quien puede o no lograr la recaudación de la cuota patronal, cuando por ejemplo se canalizan los apoyos y ayudas económicas del gobierno municipal. Es el delegado quien controla las listas de los posibles beneficiarios.

Cuando no cooperan, pues todos necesitamos de aquí del pueblo, y ya al final de la feria hacemos las cuentas y entregamos las listas y todo, y el que viene en blanco, sacamos otra lista de todos los que no cooperaron y se la llevamos al delegado, porque, por ejemplo, vienen ayudas de Coatepec y allí sí bien que van a pedir. Y entonces el delegado les dice: "Pues te anoto, pero estás en blanco; me tienes que dar una feria". (Santiago, 33 años)

En Estados Unidos, los migrantes no documentados son los más renuentes a cooperar, o bien, son los que cooperan en menor proporción, debido a que no siempre pueden asistir y divertirse en dicho evento. Sin embargo, José, quien es cobrador en Woodstock, Illinois, señala que la población migrante no documentada coopera, porque su cuota (por arriba de 200 dólares) les brinda el derecho de obtener el video de la fiesta, donde pueden ver a sus familiares y de alguna manera sentirse partícipes de la celebración.

A pesar de los diversos vínculos económicos y sociales que involucra la organización de la fiesta, de momento pareciera que se tratara de poblaciones separadas o divididas, con intereses muy diferentes. No obstante esta división, el ambiente que se vive durante la fiesta parece dejar atrás las diferencias e intereses desarticulados, pues aquí es cuando las visitas temporales de los migrantes trascienden de una práctica económica a una práctica social, familiar y comunitaria que revive los vínculos, permite los reencuentros y la convivencia entre una misma población (ver Imagen $\mathrm{N}^{\circ} 1$ ).

\section{Imagen 1. Familiares y amigos conviviendo durante la fiesta patronal}

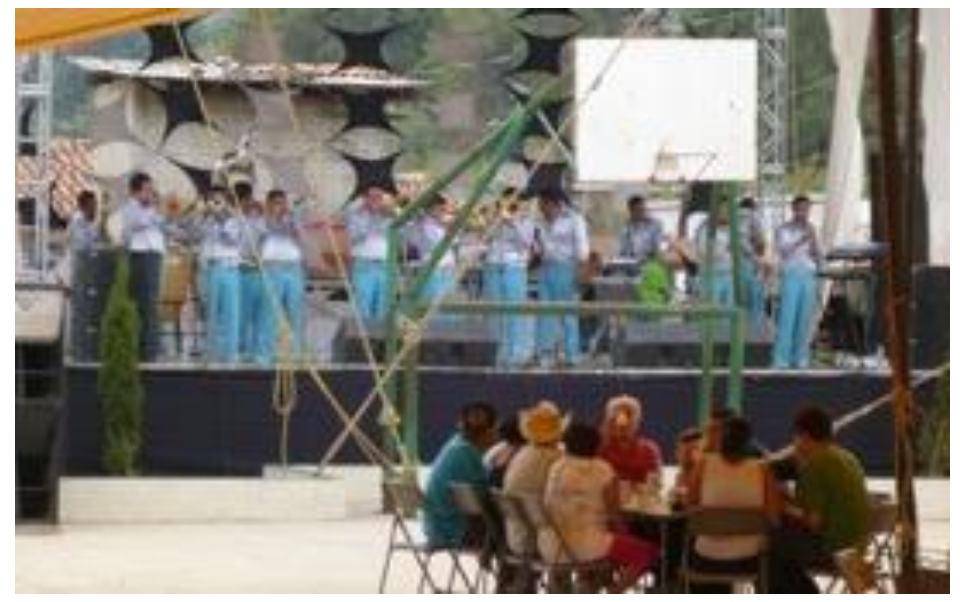

Fuente: Jardón (2011).

De ahí que es necesario puntualizar su construcción social como espacio y recurso que vincula y arraiga a la población emigrante, pues se trata de un evento que fomenta la 
comunicación transfronteriza, promueve el envío de importantes flujos de remesas prestigio, estimula el retorno temporal de los emigrantes regulares, al tiempo que vincula y difunde las tradiciones entre las nuevas generaciones de origen vuelteño, facilita la entrega directa de las remesas familiares y en especie, en la medida en que la gran parte de los 'norteños' trae consigo obsequios y antes de partir dejan a sus familiares ciertas cantidades de dinero. En suma, la fiesta patronal es una práctica que salvaguarda y fortalece los lazos entre los que se quedan y los que se van, pero no como poblaciones separadas, sino como una comunidad que se vincula por su origen y sentido de pertenencia.

\section{Remodelación de la iglesia}

En torno al componente religioso, observamos también que el fervor, creencia y veneración a la Santa Cruz se configuró como una necesidad sobre la que descansa el origen de la organización, y el envío de las remesas comunitarias, como una práctica transnacional, pues con el propósito de ampliar la Iglesia de la Santa Cruz se pide por vez primera la ayuda de la población emigrante en Estados Unidos. En 1980 se realizó la primera colecta y se iniciaron los trabajos de la ampliación del templo, siendo por entonces cuando se construyeron el salón de la iglesia y los costados que le dieron a la construcción la forma de cruz. No obstante, desde este momento empezaron a crearse conflictos relativos al manejo y la administración de los dineros, dado que la gente del pueblo rumoreaba que los responsables de la obra se habían robado parte del dinero. Además de los rumores, la ejecución de esta obra creó falsas perspectivas entre la población emigrante, la cual llegó a suponer que 'todo venía por parte de ellos'.

En 1999, dirigidos por el párroco José, se integró un comité responsable de la restauración y decoración de la iglesia; sin embargo, seleccionar a los responsables no fue fácil, dado el ambiente de recriminación y desconfianza experimentado durante la obra de ampliación. Finalmente, fue la presión ejercida por el cura el antecedente que permitió la restauración del templo, la participación del migrante colectivo y el fortalecimiento de los patrones de envío de las remesas comunitarias (ver Imagen $\mathrm{N}^{\circ} 2$ ).

Aunque previa a esta organización, la creencia de que 'todo venía de Estados Unidos' supuso una división entre la población de Las Vueltas y la población de Estados Unidos, en tanto el comité responsable de la obra tenía como objetivo restaurar la iglesia, pero también "demostrarle [a los de Estados Unidos] que en Las Vueltas la gente podía organizarse y hacer las cosas" (Gonzalo, 35 años). 
Imagen 2. Ampliación de la Iglesia de la Santa Cruz y salón

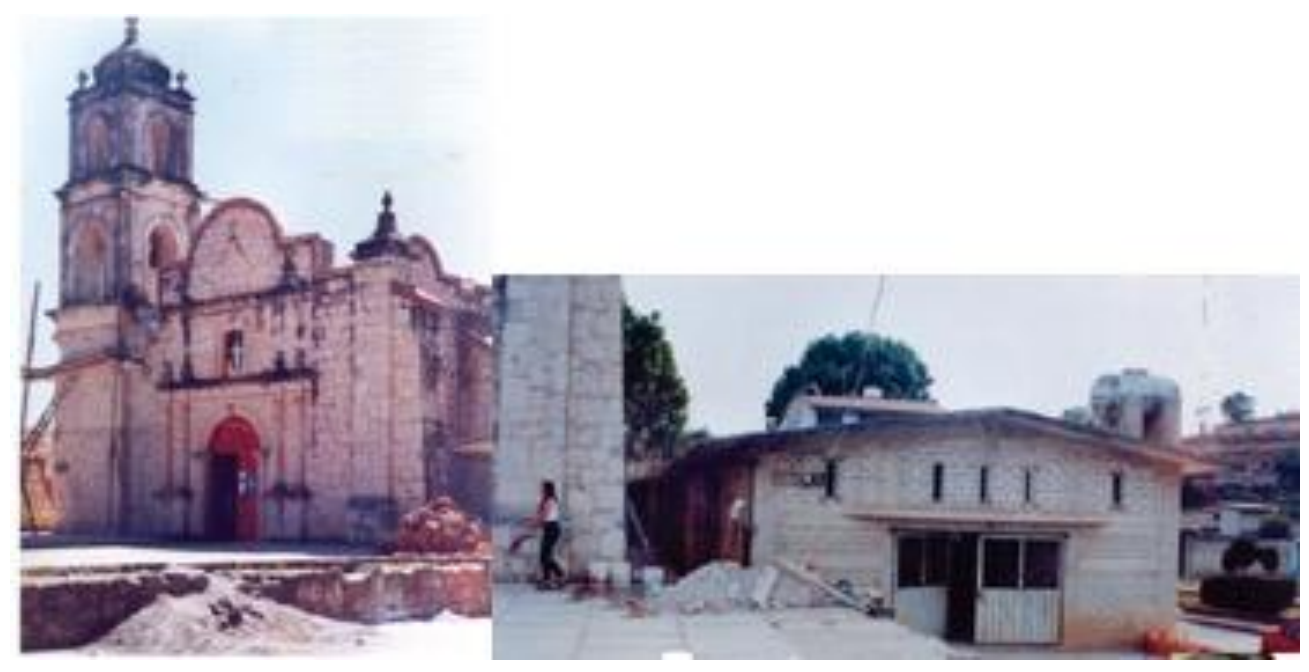

Fuente: Archivo fotográfico familia Domínguez (1999).

La decisión de trabajar como dos comunidades independientes despertó entre la población emigrante el deseo de cooperar, pues sabían que se habían iniciado los trabajos de restauración, pero no se explicaban por qué no se les pidió su ayuda. Estrategia o no, la separación entre los de aquí y los de allá tuvo como corolario la cohesión de la comunidad, pues el retorno temporal de los migrantes permitió que mucha de esta población se percatara del avance en los trabajos realizados y decidiera por sí misma cooperar para restaurar su iglesia.

Así entonces, haber ignorado e iniciado los trabajos de restauración desvinculando a los 'norteños' lastimó y quizás cuestionó su membresía comunitaria, por lo que en aras de contribuir para su pueblo iniciaron un proceso masivo de envío de remesas de dólares. Entre las estrategias puestas en juego por esta población para lograr la conclusión de la obra surgió formalmente la lista de cooperaciones, como un instrumento que permitió censar a la población vuelteña en Estados Unidos, Toluca y Ciudad de México.

Finalmente, en medio de conflictos, desconfianzas y acusaciones, la organización social de la comunidad vuelteña en México y Estados Unidos culminó en una inversión de aproximadamente tres millones de pesos durante el período 1999-2002, que no solo permitió la restauración de su iglesia, sino que fortaleció las expectativas de esta población por "mejorar y hacer algo por el pueblo" (Moisés, 48 años), además de vincular y recuperar los lazos con su población emigrante (ver Imagen $\mathrm{N}^{\circ} 3$ ). 


\section{Imagen 3. Restauración de la Iglesia de la Santa Cruz}

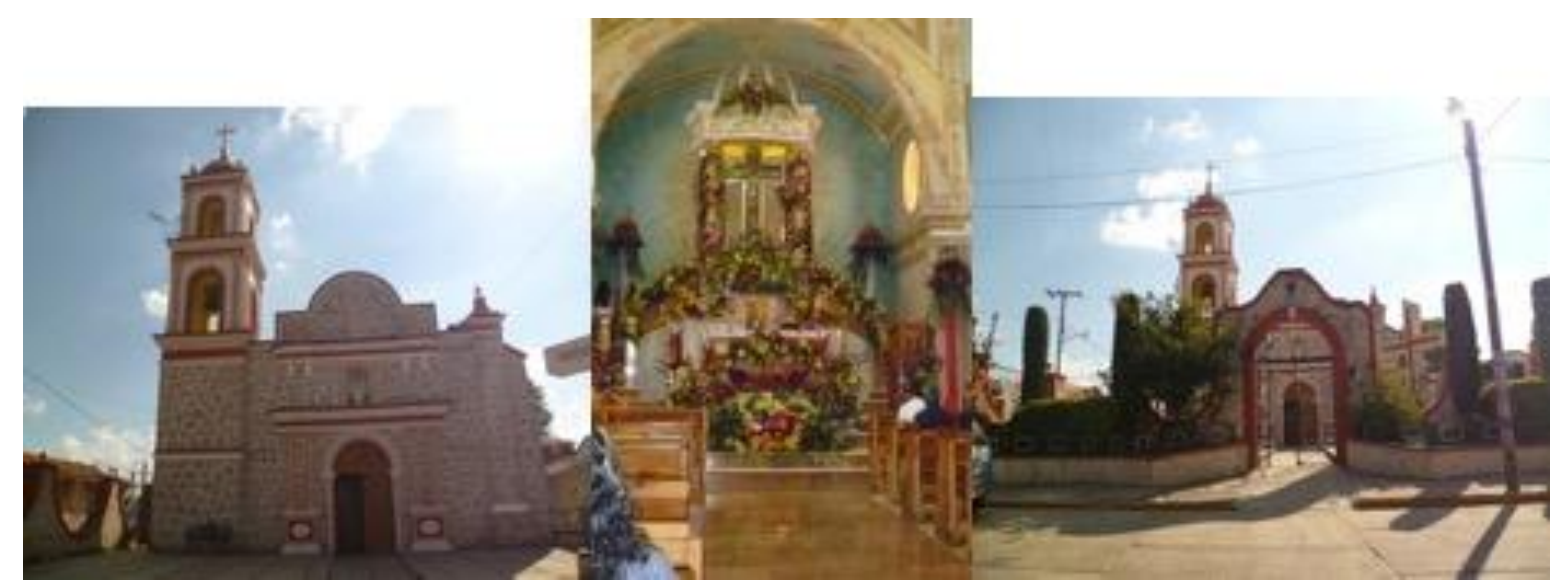

Fuente: Jardón (2011).

\section{Organizaciones políticas}

Como actores locales, los comités o clubes de migrantes son organizaciones que facilitan la movilización transnacional de los capitales económicos y socioculturales, además de que conforman un recurso mediante el que los migrantes como actores sociales pueden participar e involucrarse en la planeación del desarrollo comunitario. En Las Vueltas, el ahora Club de Mexiquenses de Santa Cruz Las Vueltas tiene su origen en los procesos de organización promovidos por líderes locales para ejecutar proyectos orientados a embellecer su comunidad de origen.

Sin embargo, el reconocimiento y nombramiento oficial del Club de Migrantes fue el resultado de una gira que el exgobernador Arturo Montiel realizó al estado de Illinois en noviembre de 2003, para vincularse con los mexiquenses radicados en ese condado. Aunque originalmente no estaba previsto que Montiel visitara el suburbio de Woodstock, la relación y afiliación al Partido Revolucionario Institucional (PRI) de Francisco, quien se reconoce y es reconocido por parte de la población vuelteña como uno de los principales líderes comunitarios, permitió que se lograra este objetivo.

El recibimiento que los vuelteños en Woodstock ofrecieron al exgobernador, así como la exposición y congruencia alcanzada por Francisco para lograr conseguir el financiamiento del gobierno estatal en la ejecución de diversos proyectos comunitarios, requirieron de la integración formal del grupo de actores que llegó a constituir el primer y hasta ahora único Club de Migrantes originarios del municipio de Coatepec Harinas (ver Imagen $\mathrm{N}^{\circ} 4$ ). 


\section{Imagen 4. Reunión del exgobernador Arturo Montiel con la población migrante de Las Vueltas en Woodstock, Illinois}

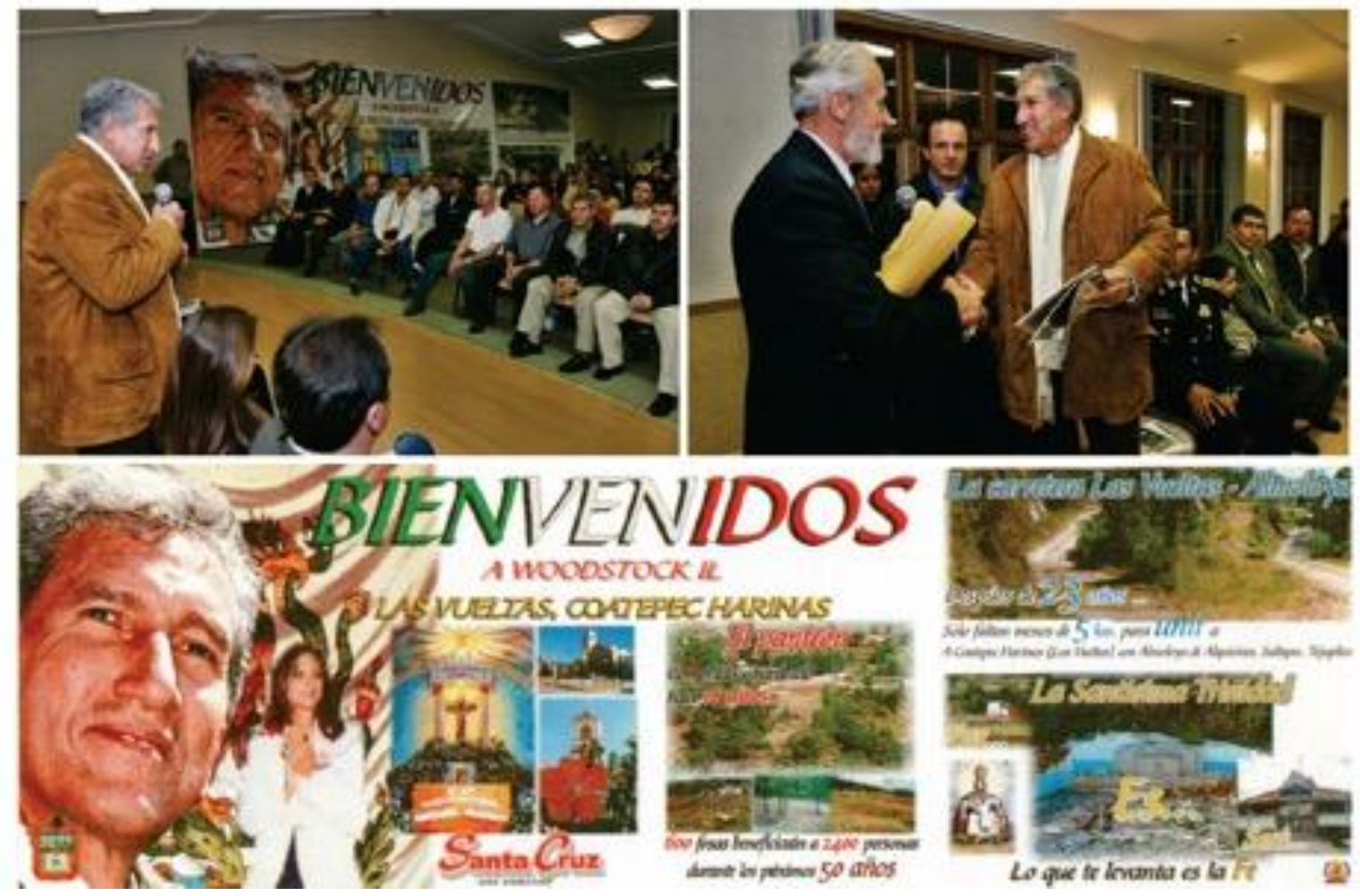

Fuente: Archivo fotográfico de la familia Domínguez (2003).

En la narrativa de Francisco, vemos que en la integración de las organizaciones de migrantes juega un papel importante la participación de intelectuales y líderes comunitarios que tienen capacidad de relacionarse en la arena política y de promover estrategias que rebasan la intervención municipal e involucran a figuras políticas estatales, de las que saben es probable la gestión de apoyos para financiar y materializar sus propias nociones de desarrollo comunitario.

Cuando se da que va a ir Montiel, yo le hablo a mi gente [en Estados Unidos], un grupo muy sólido, muy eficaz, jaladores y todo. En aquel entonces éramos unos 700 habitantes de Las Vueltas allá, y el salón en Woodstock estaba a reventar. Para esa ocasión yo diseñé una lona; en ella le puse la foto de él [Arturo Montiel], la de su esposa, la de la Santísima Cruz y las tres obras: el panteón, la Trinidad y la carretera. Ya llegando Montiel al salón empezó a tocar el mariachi, estuvo muy contento, y cuando empezó la presentación y me tocó a mí agarrar el micrófono, pues obviamente en estas reuniones generalmente empiezas: "Oiga, queremos esto, queremos lo otro", pero yo no; yo empecé de una manera diferente y le dije: "Señor gobernador, permítame presumirle lo que hemos hecho como pueblo, un pueblo tan chiquito como Las Vueltas: hicimos una iglesia y con pura cooperación de la gente, y queremos compartirlo con usted porque para nosotros 
es un gran orgullo, y quizá a usted le interesa ser partícipe de algunos otros proyectos que tenemos". Entonces, a raíz de eso fue que cuando se tuvo que hacer formalmente, se puede decir que a nivel de gobierno del Estado que existiera ese comité, ese Club. (Francisco, 53 años)

Además de los proyectos de obra, el Club de Santa Cruz Las Vueltas interviene en el campo social apoyando a los hogares vulnerables económicamente (en Las Vueltas y Estados Unidos), en situaciones de enfermedad o deceso de algún familiar. No obstante, la prestación de esta ayuda comunitaria transnacional está condicionada por un principio de reciprocidad compartida, en la medida en que únicamente pueden beneficiarse los hogares comprometidos con las costumbres y tradiciones locales.

El servicio que nosotros prestamos es ayudar. Nosotros ya tenemos una lista de las personas que han dado su cooperación [para la fiesta patronal]. Usamos esa lista por si alguien fallece allá, para colectar dinero y enviar los restos para acá y por medio de esas listas era más fácil. También cuando alguien fallece en Las Vueltas juntamos dinero para ayudar a la familia. De esa manera es que ayudamos a la gente. Además de que hemos hecho cosas como la restauración de la iglesia y la construcción de La Trinidad. (Teodoro, 38 años)

En suma, los ejemplos aquí recuperados, por un lado ponen en evidencia que las prácticas transnacionales abarcan ámbitos distintos (económico, político, religioso y cultural), aunque al mismo tiempo se interconectan entre sí; por otro lado se observa también que dichos vínculos se sustentan tanto en las relaciones sociales, de parentesco y amistad, como en las tecnologías de transporte y comunicación, que posibilitan el establecer acuerdos e involucrarse con cierto dinamismo, constancia y formalidad para realizar actividades y proyectos acordes con las necesidades sentidas que afianzan la pertenencia de esta población.

\section{Conclusiones}

Las prácticas transnacionales aquí presentadas ponen en evidencia la complejidad en la dinámica migratoria hacia Estados Unidos, que no es exclusiva de Las Vueltas, sino que se manifiesta en la región sur del Estado de México. La masividad y concentración de las migraciones de la población de Las Vueltas fortaleció los vínculos entre 'los de aquí' y 'los que están allá' mediante la puesta en marcha de un conjunto de prácticas transnacionales dirigidas a vigorizar los vínculos sociales, económicos y políticos comunitarios. De este modo, la identidad, el arraigo y el sentido de pertenencia comunitario se vieron robustecidos por estos intercambios, al tiempo que han permitido mejorar las condiciones socioeconómicas de la comunidad y los hogares.

Es importante señalar que en el ejercicio de las tantas prácticas que han robustecido los vínculos de los migrantes con su pueblo de origen, observamos que, en la puesta en marcha de prácticas como la organización de la fiesta patronal de la Santa Cruz y la gestión de 
proyectos de obra comunitaria, se pone de relieve la posición jerárquica de 'los norteños' para decidir y ejecutar los acuerdos bajo una visión impositiva y dominante. En este sentido, entre la población migrante de Las Vueltas parece haberse configurado una especie de élite migratoria, en la medida en que el peso económico de sus remesas colectivocomunitarias aparentemente les otorga un poder de decisión sobre el que la población local debe ceder ante la incertidumbre de que dejen de aportar. Así las cosas, entender las lógicas de funcionamiento que precisan la existencia de dichos vínculos se encuentra entre las tareas pendientes que deja la exploración del estudio de caso aquí expuesto.

\section{Referencias}

Ariza, M. y Portes, A. (2007). La migración internacional de mexicanos: escenarios y desafíos de cara al nuevo siglo. En M. Ariza y A. Portes (Coords.), El país transnacional. Migración mexicana y cambio social a través de la frontera (pp. 1151). Ciudad de México: Universidad Nacional Autónoma de México.

Baca, N. (2011). Lógicas de circulación y migración femenina del sur mexiquense a Estados Unidos (Disertación doctoral sin publicar). Universidad Nacional Autónoma de México, Ciudad de México.

Becerril, O. (2007). Lucha cultural por la dignidad y los derechos humanos. Transmigrantes mexicanos en Canadá contendiendo el género, la sexualidad y la identidad (Disertación doctoral sin publicar). Universidad Autónoma Metropolitana, Unidad Iztapalapa, Ciudad de México.

Dore, C., Hernández, E. Vásquez, O., Portes, A., Guarnizo, L. y Landolt, P. (2003). Cartografía del transnacionalismo dominicano: amplias y estrechas prácticas transnacionales. En A. Portes, L. Guarnizo y P. Landolt (Coords.), La globalización desde abajo: transnacionalismo inmigrante y desarrollo. La experiencia de Estados Unidos y América Latina (pp. 159-192). Ciudad de México: FLACSO.

Durand, J. (2007). Remesas y desarrollo. Las dos caras de la moneda. En P. Leite, S. Zamora y L. Acevedo (Coords.), Migración internacional y desarrollo en América Latina y el Caribe (pp. 221-236). Ciudad de México: CONAPO.

Faist, T. (2000). Transnationalization in international migration: implications for the study of citizenship and culture. Ethnic and Racial Studies, 23(2), 189-222.

Faist, T. (2006). The transnational social spaces of migration. COMCAD Working Papers, 10. Recuperado de https://www.ssoar.info/ssoar/bitstream/handle/document/35069/ssoar-2006-faistThe_transnational_social_spaces_of.pdf?sequence $=1 \&$ isAllowed=y\&lnkname=ssoa r-2006-faist-The_transnational_social_spaces_of.pdf 
Giorguli, S. e Itzigsohn, J. (2006). Diferencias de género en la experiencia migratoria. Transnacionalismo e incorporación de los migrantes latinos en Estados Unidos. Papeles de Población, 12(47), 9-37.

Glick Schiller, N., Basch, L. y Blanc-Szanton, C. (1992). Transnationalism: A new analytic framework for understanding migration. En N. Glick Schiller, L. Basch y C. BlancSzanton (Coords.), Towards a Transnational Perspective on Migration. Race, class, ethnicity and nationalism reconsidered (pp. 1-24). New York: Academy of Sciences.

Guarnizo, L. E. (2007). La nueva configuración de los estudios sobre migración. En M. Ibarra (Coord.), Migración. Reconfiguración transnacional y flujos de población (pp. 23-47). México: Universidad Iberoamericana.

Guarnizo, L. E., Portes, A. y Haller, W. (2003). Assimilation and transnationalism: determinants of transnational political action among contemporary migrants. American Journal of Sociology, 108(6), 1211-1248.

Guarnizo, L. E. y Smith, M. (1999). Las localizaciones del transnacionalismo. En G. Mummert (Coord.), Fronteras fragmentadas, identidades múltiples (pp. 87-110). Zamora: El Colegio de Michoacán.

Hondagneu, P. (2007). La incorporación del género a la migración: "no sólo para feministas-ni sólo para la familia. En M. Ariza y A. Portes (Coords.), El país transnacional. Migración mexicana y cambio social a través de la frontera (pp. 423-451). Ciudad de México: Universidad Nacional Autónoma de México.

Jardón, A. (2013). Nuevos escenarios en los procesos de organización social de la migración internacional en Las Vueltas, Estado de México (Tesis doctoral). El Colegio de Michoacán, Zamora, México.

Levitt, P. y Jaworsky, N. (2007). Transnational migration studies: past developments and future trends. Annual Review of Sociology, 33(1), 129-152.

Levitt, P. y Glick Schiller, N. (2006). Perspectivas internacionales sobre migración. En A. Portes y J. DeWind (Coords.), Repensando las migraciones. Nuevas perspectivas teóricas y empíricas (pp. 191-229). Ciudad de México: Universidad Autónoma de Zacatecas.

Levitt, P., DeWind, J. y Vertovec, S. (2003). International perspectives on transnational migration: an introduction. International Migration Review, 37(3), 565-575.

Portes, A. (2005). Convergencias teóricas y evidencias empíricas en el estudio del transnacionalismo de los inmigrantes. Migración y Desarrollo, 4(1), 2-19.

Rivera, L. (2007). Repensando el estudio de las migraciones contemporáneas en las ciencias sociales: algunas contribuciones desde la perspectiva transnacional. En A. Panfichi (Coord.), Aula magna: migraciones internacionales (pp. 19-38). Lima: Pontificia Universidad Católica del Perú.

Velasco, L. (2002). El regreso de la comunidad: migración indígena y agentes étnicos. Los mixtecos en la frontera México-Estados Unidos. Ciudad de México: El Colegio de México, Centro de Estudios Sociológicos. 